\title{
Design and Application of Subway Construction Site Management System
}

\author{
Pin Zhu ${ }^{1, a}$,Xinyi Chen ${ }^{2, b,{ }^{,}, F u c h e n g ~ W a n ~}{ }^{3, c}$,Tengfei Gao ${ }^{4, d}$ \\ ${ }^{1}$ Northwest University for Nationalities, National languages Information Technology research \\ institute, Lanzhou city, Gansu province, China \\ ${ }^{2}$ Northwest University for Nationalities, National languages Information Technology research \\ institute, Lanzhou city, Gansu province, China \\ ${ }^{3}$ Northwest University for Nationalities, National languages Information Technology research \\ institute, Lanzhou city, Gansu province, China \\ ${ }^{4}$ China Railway Tunnel Bureau three,Shenzhen,Guangdong Province,China \\ a18272735975@163.com,b1154293638@qq.com,c306261663@qq.com, \\ d1072278516@qq.com \\ *Zhupin
}

\begin{abstract}
Keywords: construction site, management system, design.
Abstract. With the continuous development of China's social economy and people's quality of life requirements continue to improve, the growth of urban population has brought the problem of traffic congestion, in order to better solve this problem, the construction of various subways and tunnels has become the main mode of development of urban rail transit in China.In order to facilitate the management staff in real time to grasp the construction site of the tunnel construction and real-time communication with the construction staff,construction management system is essential.In many of our management system, administrative office management system is the core,but in the construction site management system is almost blank.
\end{abstract}

\section{Introduction}

At present, the United States and other developed countries attach great importance to the application of information technology in the construction industry, especially in the construction site application. China in the mid-90s, the Ministry of Construction of the first implementation of the "Jin Jian" project, China Unicom's Ministry of Construction, provinces, autonomous regions and municipalities in charge of construction administrative departments, opening e-mail system, which accumulated experience.

\section{Subway construction site management system design of the main content}

Subway construction site management system to make up for the construction site before the blank in this area, mainly in three areas to achieve the original part of the construction site. First, to achieve automatic generation of cost analysis reports, greatly improving efficiency.Cost analysis module is to make up for the blank before the construction management system, through the material department to continuously adjust the price of the main material, by entering the blueprint in advance database, automatically generate reports. Second, real-time monitoring of the construction site security risks, timely reporting. Subway tunnel construction site management system not only in the government work, in the construction site can also achieve intelligent site, to maximize the construction site to prevent the occurrence of casualties, which is the construction site to achieve intelligent significance. .

\subsection{Function module diagram}

The system of the demand analysis of the overall functional module design, the main realization of the six major functional modules, respectively 
Respectively, for security monitoring, module association, program management, vehicle management, cost analysis and system management. The specific requirements for each functional module are shown in Figure 1.

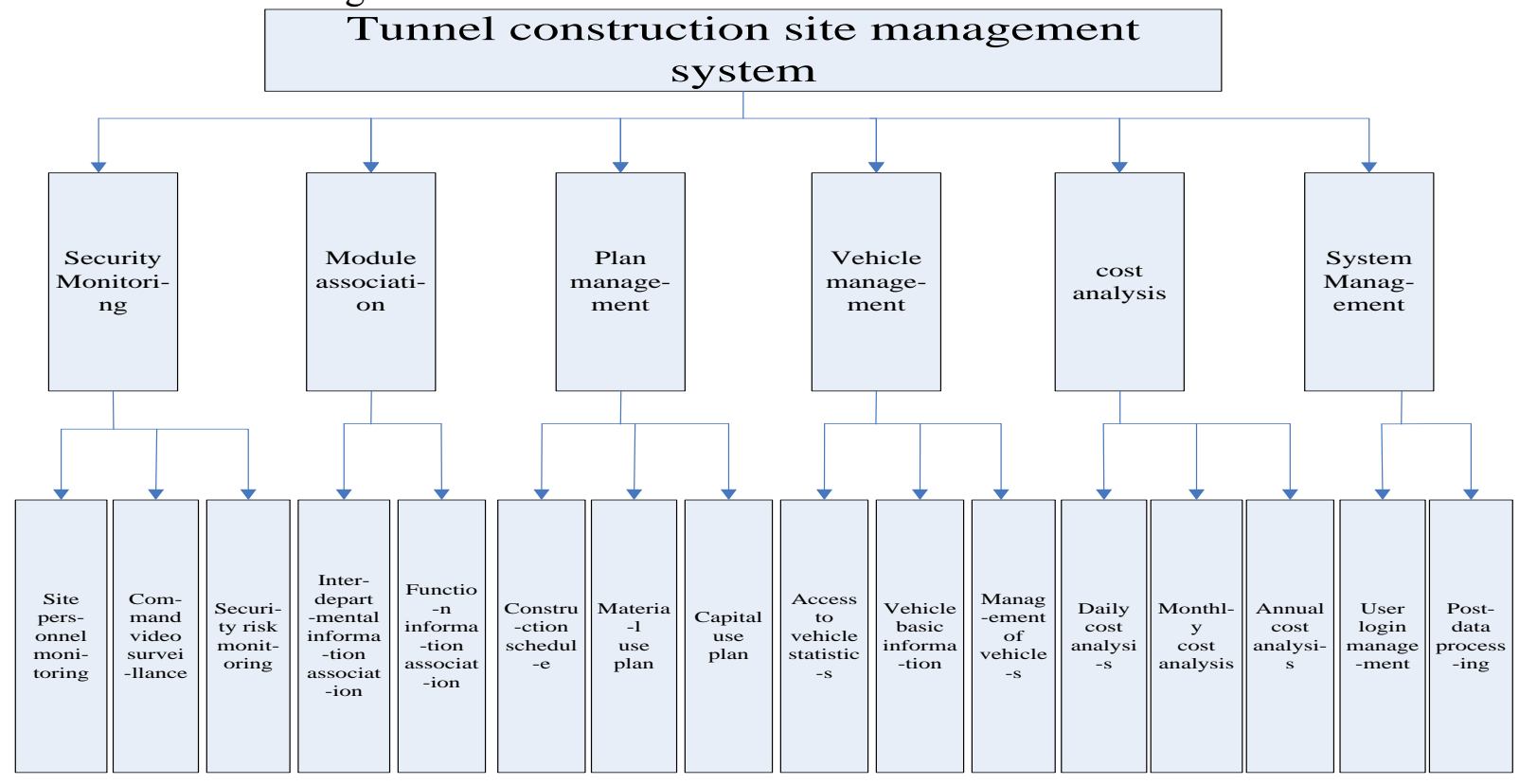

Figure 1 management system specific function module diagram

(1)safety monitoring: tunnel construction site safety is more important than the safety of the ground building, the higher the risk factor, through the remote video monitoring construction site operations, you can keep abreast of the safety of the scene, and timely view the scene Security risks.

(2)module association: in the past site construction management system for the construction of the various functions of the design are more perfect, but for the relationship between the various functions of the design between the blank.

(3)Project management: In a construction unit, the construction plan is the prerequisite to complete the construction, construction schedule as long as the construction site is recorded construction progress, material use plan is the material procurement, application, use, consumption and other records.

(4)Vehicle management: vehicle management module to solve the shortage of vehicle resources, the different models, different uses of vehicles classified, the basic situation of the vehicle registration, vehicle scheduling applications.

(5)Cost analysis: the current construction unit is mainly used in the cost analysis method so that the construction site by the day of the technician in the day after the end of the construction/

(6)System management: system management is mainly for the system of late data maintenance, and system access rights management.

\subsection{System design E-R diagram}

The E-R diagram of the system expresses the real world from the perspective of system attributes, providing the attributes and relationships of different entity types in the process of its description. But in the description of the time to follow a certain concept to complete the work, such as the common concept of structure, the concept of structure is the most important part of the database, it is the demand analysis of the abstract model into the concept of conceptual model. 


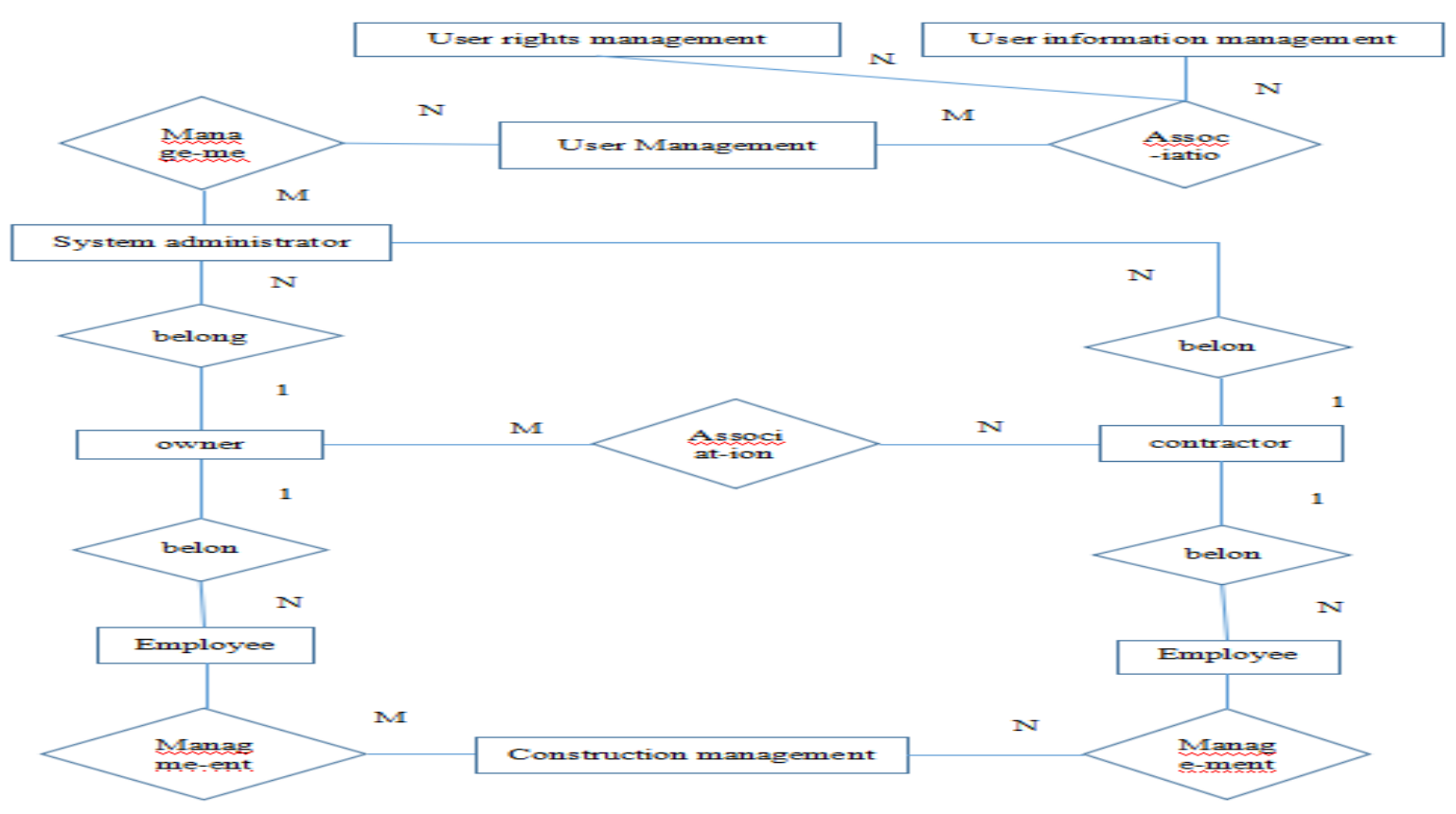

Figure 2 Demand Analysis Total E-R Chart

As shown in Figure 2, the system has two main properties of the owner and the contractor. They belong to the many-to-many relationship. Owners are owners and contractors. They belong to contractors. They are one-to-many, Contractors Employees co-management projects are many-to-many relationships.

\section{Technical structure of subway construction site management system}

Because the user of this system mainly includes administrators, owners, contractors, employees, etc., so there are more scattered users, multi-user, cross-platform features.

\subsection{Technical route}

The system is mainly for the construction site of the construction site, so the system must consider the reusability, after the completion of a project to clear all the data in the system, the original unit after the data backup, the system of the original unit of all the data and system maintenance next use. This is an important factor to consider when designing the system. The overall technical roadmap of the system is shown in Figure 3 below. 


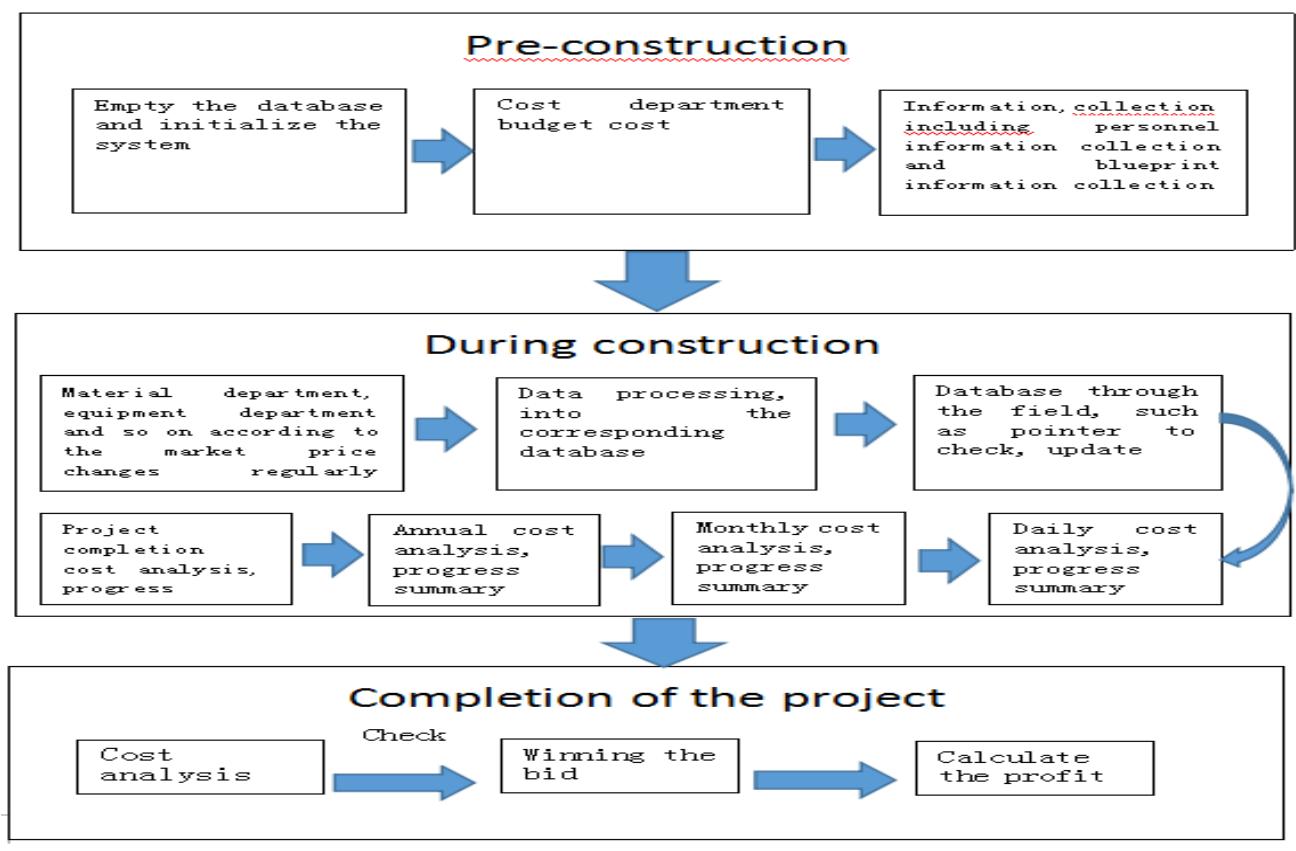

Figure 3 Technical roadmap

As shown in Figure 4, when the construction unit to determine the successful bidder after the bid, the cost of the Department of the blueprint for the cost, and the bid to check the funds. Early use of the system to the system initialization, clear the contents of the database, and then the collection of information, including personnel information and blueprint information collection. In the construction period, the first through the field pointer, time, etc.

\section{Summary}

The main is the construction of the construction site, how to do in the construction site to achieve office automation, the use of management system for on-site management, including safety management, reduce the occurrence of accidents, and automatically generate reports, no longer manually cost, Are the main purpose and significance of the system.

\section{References}

[1] Guofeng Ma , Meizeng Tu . Restrictive factors in the application of project schedule ma0

[2] nagement [J]. Journal of Management Engineering, 2002,4: 6366.

[3] Xianglu Li , Zongmin Li . Management Information System [M]. Nanjing: Nanjing University Press, 2007, 1: 104-152.

[4] Hui Cai .Study on the development trend of project management and the countermeasures of Chinese enterprises [J] .Pulfur and phosphorus design and powder engineering, 2003,4: 3941

[5] Fayez F. Boctor. Some efficient multi heuristic procedures for Resource Constrained Project.

[5] Alan Cen. Project Management Raiders [M]. Lu Hai, Xu Baoshan. Guangzhou: World Book Publishing House, 2002.

[6] Application of Informatization in Project Construction Management [J]. Management Manager, 2009 (3): 45-48 